\title{
The effect of scopolamine on reference and working memory in pigeons
}

\author{
ANGELO SANTI, COLLEEN HANEMAAYER, and WILLIAM REASON \\ Wilfrid Laurier University, Waterloo, Ontario, Canada
}

\begin{abstract}
A comparison of the effects of scopolamine hydrobromide on working memory and reference memory in White Carneaux pigeons was undertaken by means of a modified delayed matchingto-sample procedure. Performance on working-memory trials was disrupted by decreases in sample duration and intertrial interval and by increases in delay interval. Performance on reference memory trials was not disrupted by any of these parametric manipulations. In Experiment 1, the pigeons received injections of scopolamine hydrobromide $(0.01,0.05$, or $0.1 \mathrm{mg} / \mathrm{kg})$, scopolamine methyl bromide $(0.1 \mathrm{mg} / \mathrm{kg}$ ), or saline prior to test sessions. In Experiment 2, the pigeons received injections of scopolamine hydrobromide $(0.01$ or $0.03 \mathrm{mg} / \mathrm{kg})$, scopolamine methyl bromide $(0.03 \mathrm{mg} / \mathrm{kg})$, or saline. In both experiments, scopolamine hydrobromide had greater disruptive effects on working-memory trials than on reference-memory trials. The centrally active form of scopolamine disrupted working-memory trial accuracy more than the peripherally active form. However, no drug dose $\times$ delay interval interaction was obtained. Thus, the interference on working-memory-trial accuracy produced by central cholinergic blockade would not appear to be due to alterations in the active maintenance of information during the delay interval.
\end{abstract}

Reference memory is regarded as a relatively stable knowledge base that is developed as a result of successful acquisition of a discrimination. It is assumed to consist of information concerning which responses to make for particular stimulus sequences, which outcomes will follow, and so on. In addition to reference memory, certain tasks involving conditional discriminations are thought to require an additional type of memory, working memory, which is conceived of as short term and limited in capacity (Honig, 1978, 1984; Roitblat, 1982, 1984). Behavioral tasks that dissociate reference memory from working memory have been used to study the effects of brain lesions in rats, monkeys, and human amnesics. Olton and Papas (1979) studied rats' spatial memory with a 17-arm maze. Nine of the arms were unbaited and 8 were baited. The unbaited arms and baited arms remained the same for each session. Thus, reference memory alone could be used to avoid arms that were never baited, but working memory was needed to avoid arms that had been baited but already visited during a session. Following lesions of the fimbria-fornix, one of the major extrinsic connections of the hippocampus, rats displayed a temporary disruption of reference memory but a more permanent disruption of working memory. Similar results were reported by Walker and Olton (1984). Zola-Morgan, Squire, and Mishkin (1982) found that conjoint amygdala-hippocampal lesions in monkeys produced virtually no deficit in a visual discrimination task requiring only reference memory, but

This research was supported by Grant A6378 from the Natural Sciences and Engineering Research Council of Canada to Angelo Santi and by a Wilfrid Laurier University research fellowship. The authors would like to thank David Peirson and Cam McRae for their assistance. Reprints may be obtained from Angelo Santi, Department of Psychology, Wilfrid Laurier University, Waterloo, Ontario N2L 3C5, Canada. severe deficits in a delayed non-matching-to-sample task when the working-memory demands were increased. These dissociations are similar to those shown by human patients with lesions of the temporal lobe including the hippocampus. For example, Sidman, Stoddard, and Mohr (1968) reported that patient H.M. had great difficulty performing a delayed matching-to-sample task in which the stimuli were ellipses and short delays were inserted between the sample and comparison stimuli. However, H.M. had no difficulty in choosing between a circle and one of a series of ellipses with choice of the circle always being correct. H.M. could perform this task accurately even when distracted from it for a few minutes. To the extent that these two tasks differ in the requirements placed on working memory, the results are consistent with those obtained with rats and monkeys following hippocampal lesions.

Individuals diagnosed as having senile dementia of the Alzheimer's type suffer from severe cognitive disturbances, including memory loss. Pathologic alterations of the hippocampal formation have been frequently implicated in this disorder, and an analysis of the specific cellular pattern of pathology suggests that the hippocampus is isolated from its normal input and output pathways (Hyman, Van Hoesen, Damasio, \& Barnes, 1984). Neurochemical deficits in the cholinergic system are also observed (Bartus, Dean, Beer, \& Lippa, 1982). In rats, anticholinergic drugs produce deficits in radial-arm performance that are similar to those produced by hippocampal lesions (Eckerman, Gordon, Edwards, MacPhail, \& Gage, 1980; Stevens, 1981; Watts, Stevens, \& Robinson, 1981). In addition, anticholinergics have been shown to disrupt working memory but not reference memory in radial-arm maze experiments conducted on $\mathrm{CD}-1$ mice 
(Levy, Kluge, \& Elsmore, 1983), preweanling rats (Rauch \& Raskin, 1984), and albino rats (Beatty \& Bierley, 1985; Wirsching, Beninger, Jhamandas, Boegman, \& ElDefrawy, 1984). Working memory performance of rhesus monkeys has also been disrupted by anticholinergic agents (Aigner \& Mishkin, 1986; Bartus \& Johnson, 1976; Bohdanecky, Jarvik, \& Carley, 1967; Penetar \& McDonough, 1983). Thus, research on humans, rhesus monkeys, rats, and mice suggests that the hippocampus and the cholinergic neurotransmitter system are involved in memory processes, particularly working memory.

\section{EXPERIMENT 1}

The purpose of the present research was to assess the effects of the cholinergic antagonist, scopolamine, on working-memory and reference-memory performance in the pigeon. If the cholinergic neurotransmitter system plays a role in the memory processes of higher vertebrates, then one would expect scopolamine to interfere with working memory more than with reference memory in the pigeon as well. Studies of the biochemistry of the pigeon brain reveal that cholinergic neurotransmitters play a very important and predominant role in the avian brain (Aprison \& Takahashi, 1965). Thus, the search for equivalent cholinergic involvement in the memory performance of pigeons would appear to be worthwhile. Consistent with this expectation, Teal and Evans (1982) found that scopolamine significantly disrupted delayed matching-tosample performance in pigeons but that DDAVP, a vasopressin analogue, and d-amphetamine had no effect. However, the dose-related decrement produced by scopolamine did not interact with the length of the delay interval. This led Teal and Evans to suggest that scopolamine was interfering with discriminative behavior generally and was not having a specific effect on working memory. In the present study, pigeons were trained in a delayed matching-to-sample task with two sets of comparison stimuli. One set consisted of red and green keylights, and the second set consisted of a vertical line and a horizontal line. The correct response to the color comparisons was to the stimulus that matched the previously presented red or green sample stimulus. This type of trial is the traditional delayed matching-to-sample trial, which requires both reference and working memory. The correct response to line comparisons was always to one particular line tilt regardless of the sample stimulus presented on that trial. On these types of trials, only reference memory is required because working memory for the nominal sample stimulus is irrelevant for choosing between line comparisons. Although this procedure appears to confound stimulus dimension differences with memory differences, the differences are in opposite directions. That is, for pigeons, color discriminations tend to be much easier than line-tilt discriminations (Carter \& Eckerman, 1975; Maki, Riley, \& Leith, 1976; Santi, Grossi, \& Gibson, 1982). However, in the present study, the manipulated variables were expected to disrupt performance more on working-memory trials than on reference-memory trials. Consequently, performance differences in favor of reference memory would be opposite to those predicted on the basis of stimulus discriminability differences. If scopolamine interferes with discriminative behavior generally, then one would expect significant disruption of both working-memory and reference-memory performance. If scopolamine's effects are more specific than suggested by Teal and Evans' data, then one would expect significantly greater disruption of working-memory performance than of reference-memory performance. In addition, the present study included injections of scopolamine methyl bromide, a quaternary anticholinergic that does not enter the central nervous system. This control agent was not used in the Teal and Evans study but is necessary in order to assess whether the disruptive effects of scopolamine hydrobromide are due to its central or its peripheral nervous system effects. Finally, it should be noted that reference-memory trials, as operationalized in the present study, constituted a simple simultaneous discrimination, whereas working memory trials constituted a delayed conditional discrimination. This difference in operationalization was required for consistency with the type of operationalization undertaken in studies of radialarm maze performance in rats (Beatty \& Bierley, 1985; Olton \& Papas, 1979; Wirsching et al., 1984), lesioning effects in monkeys (Zola-Morgan et al., 1982), and patient H.M. (Sidman et al., 1968).

Prior to drug testing, three test phases were conducted in which delay interval, intertrial interval, and sample duration were manipulated. This parametric testing was conducted to validate the procedure. It was anticipated that these manipulations would affect the working-memory trials but not the reference-memory trials. Although intertrial-interval duration has been shown to affect the acquisition of simultaneous discrimination reversals (Williams, 1971, 1976) and performance on daily reversals of homogeneous delayed matching-to-sample trials (Roberts, 1980), it was not anticipated that it would affect performance on reference-memory trials, since the simultaneous discrimination was well established and was not subject to daily reversals.

\section{Method}

Subjects. Fifteen White Carneaux pigeons, maintained at $80 \%$ $\pm 20 \mathrm{~g}$ of their ad-lib weights and housed individually with constant access to grit and water, served as subjects. All birds had had extensive experience with choice delayed matching-to-sample tasks involving color and line-orientation stimuli.

Apparatus. Four Coulbourn modular operant test cages (Model E10-10), housed individually in isolation cubicles (Model E10-20), were used. Each cubicle was equipped with a ventilation fan and baffled air intake and exhaust system. Each test cage was equipped with three horizontally aligned clear plastic keys, behind which projectors could display stimuli (red or green field, vertical or horizontal white line on a black background, white circle or white triangle on a black background, or black dot on a white background) onto a frosted rear-projection screen (Coulbourn Model E21-28). Directly below the center key was a $5.7 \times 5 \mathrm{~cm}$ opening that provided access to a hopper filled with mixed grain 
(Coulbourn Model E14-10). All experimental events and response measures were arranged and recorded by a microcomputer system located in an adjacent room.

Procedure. Eight birds were trained with a delayed matchingto-sample procedure in which each trial began with the presentation of a warning stimulus (a black dot on a white background) on the center key. A peck to the warning stimulus produced either a red or a green sample on working-memory trials and either a circle or a triangle nominal sample on reference-memory trials. The sample stimulus terminated after $5 \mathrm{sec}$ and was followed immediately by presentation of the comparison stimuli on the side keys On working-memory trials, the comparison stimuli were red and green key lights, and on reference-memory trials, they were vertical and horizontal lines. The position of the comparison stimuli on side keys was counterbalanced over trials. On working-memory trials, the correct response was to choose the comparison that matched the previously presented sample. On reference-memory trials, for half of the birds the correct response was to choose the vertical line and for the other half the correct response was to choose the horizontal line, regardless of what the previously presented sample was. A response to a side key terminated the comparison stimuli and resulted in either 3 -sec access to mixed grain if correct or a 3 -sec blackout if incorrect. Following either reinforcement or blackout, an intertrial interval of $15 \mathrm{sec}$ was spent in darkness. Each session consisted of 24 working-memory trials and 24 referencememory trials presented in six individually randomized blocks of the eight different combinations of sample and comparison stimuli counterbalanced for position on the side keys

Training continued until all birds were able to maintain performance at or above $85 \%$ correct for at least three consecutive sessions. Three test phases were then conducted in which delay interval (DI), intertrial interval (ITI), and sample duration were manipulated. Delay interval testing was carried out in three blocks of 4 days each. There were four DIs tested, $1,2,4$, and $8 \mathrm{sec}$, and only one DI duration was tested on a given day. Within each block of 4 days, each DI was tested once, with the sequence of testing randomly varied between birds and between blocks of sessions. Except for the change in DI, all aspects of a test session were identical to those described for the sessions prior to testing.

Following DI testing, the birds were returned to the baseline conditions with a DI of $0 \mathrm{sec}$. Criterion levels of performance as previously described were reestablished and ITI testing was carried out in three blocks of 3 days each. There were three ITIs tested, 1 , 5 , and $25 \mathrm{sec}$. Only one ITI duration was tested on a given day. Within each block of 3 days, each ITI was tested once, with the sequence of testing varied randomly between birds and between blocks of sessions. Except for the change in ITI, all aspects of a test session were identical to those described for baseline sessions.

Following ITI testing, the birds were returned to the baseline conditions with an ITI of $15 \mathrm{sec}$. Criterion levels of performance as previously described were reestablished, and sample duration testing was carried out in three blocks of 3 days each. There were three sample durations tested, $0.5,1$, and $5 \mathrm{sec}$. Only one sample duration was tested on a given day. Within each block of 3 days, each sample duration was tested once, with the sequence of testing varied randomly between birds and between blocks of sessions. Except for the change in sample duration, all aspects of a test session were identical to those described for baseline sessions.

Seven additional birds were given baseline training with procedures identical to those described above except that the nominal sample stimuli on reference-memory trials were the same as the sample stimuli on working-memory trials, that is, red and green colors. The sequence of events within each trial was exactly the same as described above for baseline conditions. Each session consisted of 48 trials. The 7 birds were maintained on baseline training until they achieved an overall level of accuracy of $85 \%$ or more on three consecutive sessions. Drug testing was then initiated. On drug-testing sessions, the pigeons received one of the following injections: scopolamine hydrobromide at a dose of $0.01,0.05$, or $0.1 \mathrm{mg} / \mathrm{kg}$; scopolamine methyl bromide at a dose of $0.1 \mathrm{mg} / \mathrm{kg}$; and $0.09 \%$ saline. Both drugs were purchased from Sigma Chemical Co., St. Louis, MO. All doses refer to the salt forms of the drugs, which were dissolved in normal saline. The injections were made into the pectoral muscle in a volume of $1.0 \mathrm{ml} / \mathrm{kg}$ of body weight. Injections were made 15-30 min prior to each test session. Two baseline sessions were interspersed between each drug-testing session. The birds were tested once at each of the 15 treatment combinations produced by factorially combining the five drug-treatment conditions with three delay intervals $(1,4$, and $8 \mathrm{sec})$. Each of the drug treatments was administered once before the same injection was repeated. Two different random orders of the drug-treatment conditions were generated. Four birds received one order and 3 birds received the other.

\section{Results}

The mean percentages of correct matching responses obtained during delay interval testing are presented in Figure 1. An analysis of variance performed on the test data included memory type, delay interval, and test blocks as within-subject factors. Significant effects were obtained for memory type $[F(1,7)=14.52, M S e=349.58]$, delay $[F(3,21)=8.46, M S \mathrm{e}=22.55]$, and the memory type $\times$ delay interaction $[F(3,21)=8.41, M S e=25.18]$. A simple main effects analysis revealed a significant effect of delay on working-memory trials $[F(3,21)=9.12]$, but not on reference memory trials $(F<1)$.

The mean percentage of correct matching responses obtained during ITI testing are presented in Figure 2. An analysis of variance revealed significant effects of memory type $[F(1,7)=19.69, M S e=191.62]$, ITI $[F(2,14)=$ $7.12, M S e=76.26]$, and the memory type $\times$ ITI inter-

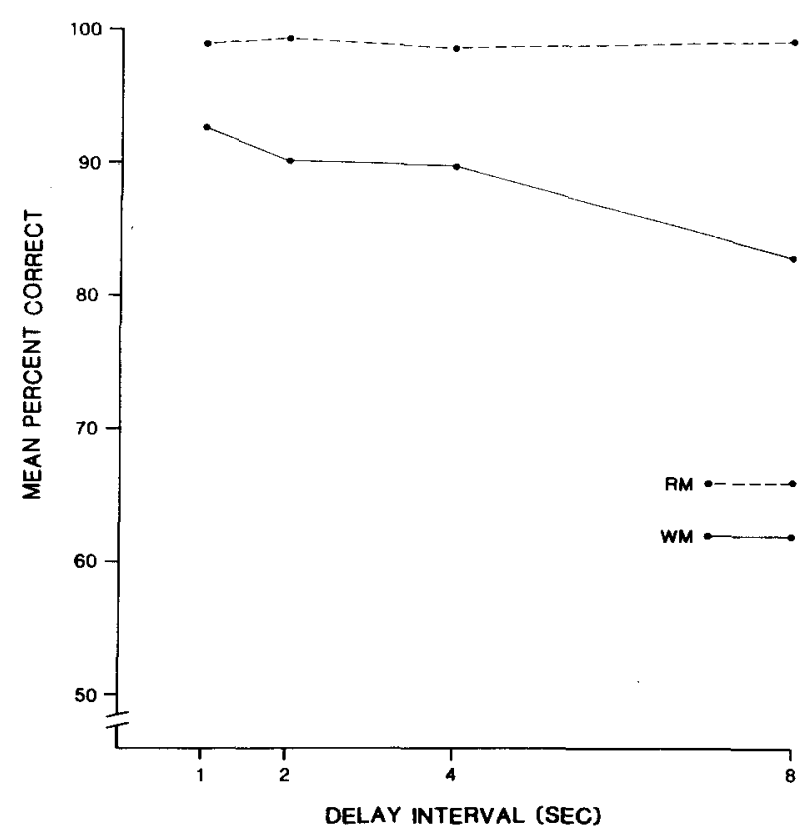

Figure 1. Mean percentage of correct matching responses on working-memory and reference-memory trials during delay interval testing. 


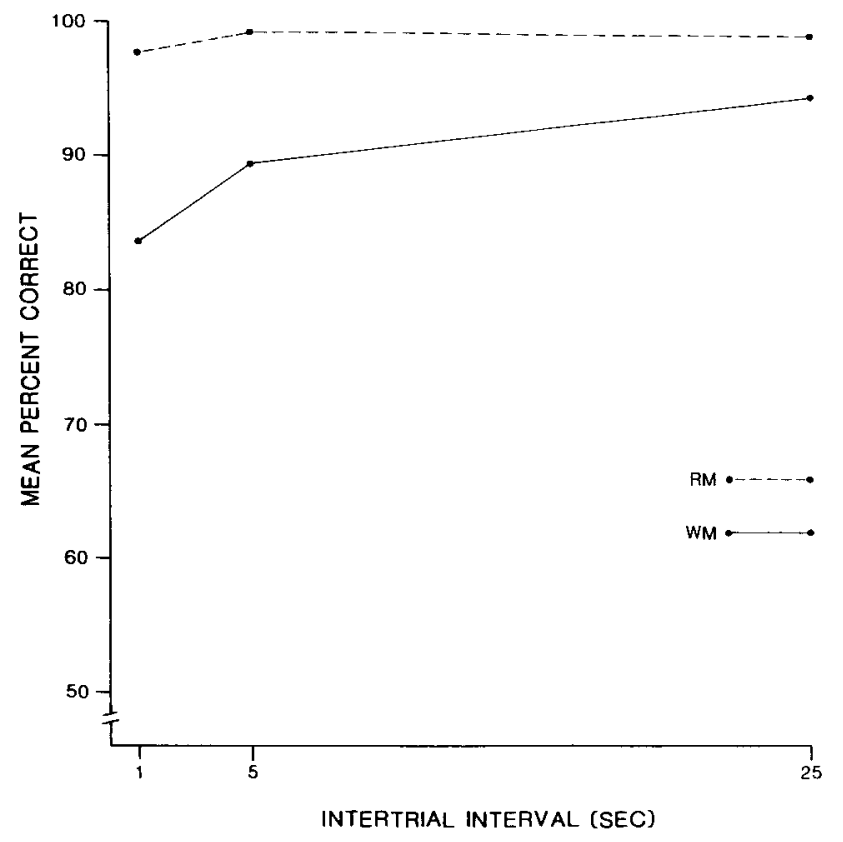

Figure 2. Mean percentage of correct matching responses on working-memory and reference-memory trials during intertrial interval testing.

action $[F(2,14)=5.94, M S e=62.51]$. A simple main effects analysis indicated a significant effect of ITI on working-memory trials $[F(2,14)=6.70]$, but no significant effect of ITI on reference-memory trials $[F(2,14)=$ 2.94].

Figure 3 presents the mean percentage of correct matching responses obtained during sample duration testing. An analysis of variance of these data indicated significant effects of memory type $[F(1,7)=39.80, M S e=331.99]$, sample duration $[F(2,14)=26.39, M S e=59.37]$, and the memory type $\times$ sample duration interaction $[F(2,14)$ $=23.08, M S e=84.77]$. A simple main effects analysis revealed a significant effect of sample duration on working-memory trials $[F(2,14)=24.93]$ but not on reference-memory trials $[F(2,14)=3.61]$.

The mean percentage of correct matching performance during drug testing sessions at the three delay intervals is shown in Figure 4. Accuracy on working-memory trials is shown in the left panel and accuracy on referencememory trials is shown in the right panel. An analysis of variance of these data revealed that accuracy on reference-memory trials was higher than on workingmemory trials $[F(1,6)=121.70, M S e=360.88]$. Type of memory interacted significantly with delay interval $[F(2,12)=4.98, M S e=67.68]$. A simple main effects analysis revealed that the effect of delay interval was significant on working-memory trials $[F(2,12)=10.94]$ but not on reference-memory trials $(F<1)$.

The overall analysis of variance also indicated a significant main effect of drug treatment $[F(4,24)=16.45$, $M S e=125.61]$ and a drug treatment $\times$ type of memory interaction $[F(4,24)=2.89, M S e=139.68]$. The effect of drug treatment was significant on both workingmemory $[F(4,24)=10.09]$ and reference-memory $[F(4,24)=13.07]$ trials. A Newman-Keuls test performed on the working-memory-trials data indicated that accuracy was significantly lower following an injection of any of the three doses of scopolamine hydrobromide or the injection of methylscopolamine than it was following an in-



Figure 3. Mean percentage of correct matching responses on working-memory and reference-memory trials during sample duration testing.



Figure 4. Mean percentage of correct matching responses on working-memory and reference-memory trials as a function of delay interval and drug condition in Experiment 1. 
jection of saline. Accuracy was also significantly lower following an injection of either 0.10 or $0.05 \mathrm{mg} / \mathrm{kg}$ of scopolamine than following an injection of $0.10 \mathrm{mg} / \mathrm{kg}$ of methylscopolamine. Among the three doses of the centrally acting form of scopolamine, the only significant difference was between the doses of 0.10 and $0.01 \mathrm{mg} / \mathrm{kg}$. A Newman-Keuls test performed for the referencememory trials data indicated that accuracy was significantly lower following an injection of 0.10 or $0.05 \mathrm{mg} / \mathrm{kg}$ of scopolamine than following an injection of saline. Accuracy was significantly lower following an injection of either 0.10 or $0.05 \mathrm{mg} / \mathrm{kg}$ of scopolamine than following an injection of $0.01 \mathrm{mg} / \mathrm{kg}$ of scopolamine. Finally, accuracy following the injection of methylscopolamine did not significantly differ from that following an injection of any of the three doses of scopolamine hydrobromide.

\section{Discussion}

In the working-memory and reference-memory tasks used in this study, the manipulation of delay interval, ITI, and sample duration produced effects on working-memory trials that were consistent with those previously reported in the usual delayed matching-to-sample task. Accuracy on working-memory trials decreased as the delay interval was increased and as the sample duration and the ITI were decreased (Nelson \& Wasserman, 1978; Roberts, 1972; Roberts \& Grant, 1976). However, accuracy on reference-memory trials was not significantly affected by any of these parametric manipulations. With respect to the delay-interval manipulation, the effects obtained when the sample stimuli on reference-memory trials were different from those on working-memory trials were equivalent to those obtained when they were the same.

On working-memory trials, injections of scopolamine significantly disrupted accuracy relative to injections of saline. In addition, injections of the centrally active form of scopolamine significantly disrupted working-memory performance more than the peripherally active form. Thus, at least in part, the effect of scopolamine on working memory is mediated by central processes. Scopolamine also disrupted performance of the referencememory task. Although the effect of scopolamine was greater on working memory than on reference memory, it is difficult to conclude that working-memory processes are more sensitive to central cholinergic blockade, since accuracy on working-memory and reference-memory components significantly differed under saline conditions. In addition, support for the hypothesis of selective effects of scopolamine on working memory would have been stronger if a significant dose $x$ delay interval interaction had been obtained. The failure to obtain this interaction may have been due to the specific doses selected for this study. The $0.10-$ and $0.05-\mathrm{mg} / \mathrm{kg}$ doses of scopolamine reduced accuracy to nearly chance levels at a 1-sec delay. Consequently, there was no opportunity to observe accelerated forgetting with these dosages. However, at the $1-\mathrm{sec}$ delay, the $0.01-\mathrm{mg} / \mathrm{kg}$ dose produced a level of accuracy that did allow for the observation of accelerated forgetting, and no such tendency appears in the data.

\section{EXPERIMENT 2}

The effects of scopolamine on working and reference memory were reexamined in this study following a number of procedural modifications. First, the stimuli used for the reference-memory task were changed from horizontal and vertical lines to $135^{\circ}$ and $45^{\circ}$ lines in order to make the discrimination more difficult and lower accuracy on reference memory trials to a level equivalent to that on working-memory trials. This would prevent the absence of a drug effect on reference-memory trials from being interpreted as being due to a ceiling effect. The second modification was that the dosages of scopolamine used were 0.01 and $0.03 \mathrm{mg} / \mathrm{kg}$. These dosages were expected to produce less disruption than the dosages of 0.05 and $0.10 \mathrm{mg} / \mathrm{kg}$ used in the first experiment, and thus provide a better opportunity to determine if dose and delay interval interacted. Finally, drug testing was carried out with two groups of birds. The same-sample group were trained with nominal sample stimuli on reference-memory trials that were the same as the sample stimuli on workingmemory trials, that is, red and green colors. The differentsample group were trained with circle and triangle as nominal samples on reference-memory trials and with red and green colors as samples on working-memory trials. This procedural variation was introduced to determine whether providing the birds wth information regarding the nature of the test stimuli would have an influence on the magnitude of the drug effects obtained.

\section{Method}

Subjects and Apparatus. Thirteen of the subjects that had served in Experiment 1 participated in this experiment. Two additional birds that had participated in the previous experiment were dropped prior to the current study because one had ceased responding and the other exhibited decreasing levels of matching accuracy during baseline sessions. The apparatus was the same as that described earlier.

Procedure. There were 6 birds in the same-sample group and 7 in the different-sample group. Each trial began with the presentation of a warning stimulus on the center key. A peck to the warning stimulus produced either a red or a green sample on workingmemory trials for both groups. On reference-memory trials, the nominal sample stimulus was either red or green for the same-sample group and either triangle or circle for the different-sample group. The sample stimulus terminated after $5 \mathrm{sec}$, and was followed immediately by presentation of the comparison stimuli on the side keys. On working-memory trials, the comparison stimuli were red and green lights; on reference-memory trials, they were line tilts of $135^{\circ}$ and $45^{\circ}$. A response to the $135^{\circ}$ line was correct for 4 birds in the different-sample group and for 3 birds in the same-sample group. A response to the $45^{\circ}$ line was correct for the remaining birds in both groups. A response to a side key on both working-memory and reference-memory trials terminated the comparison stimuli and resulted in either 3-sec access to mixed grain, if correct, or a 3-sec blackout, if incorrect. Following either reinforcement or blackout, 


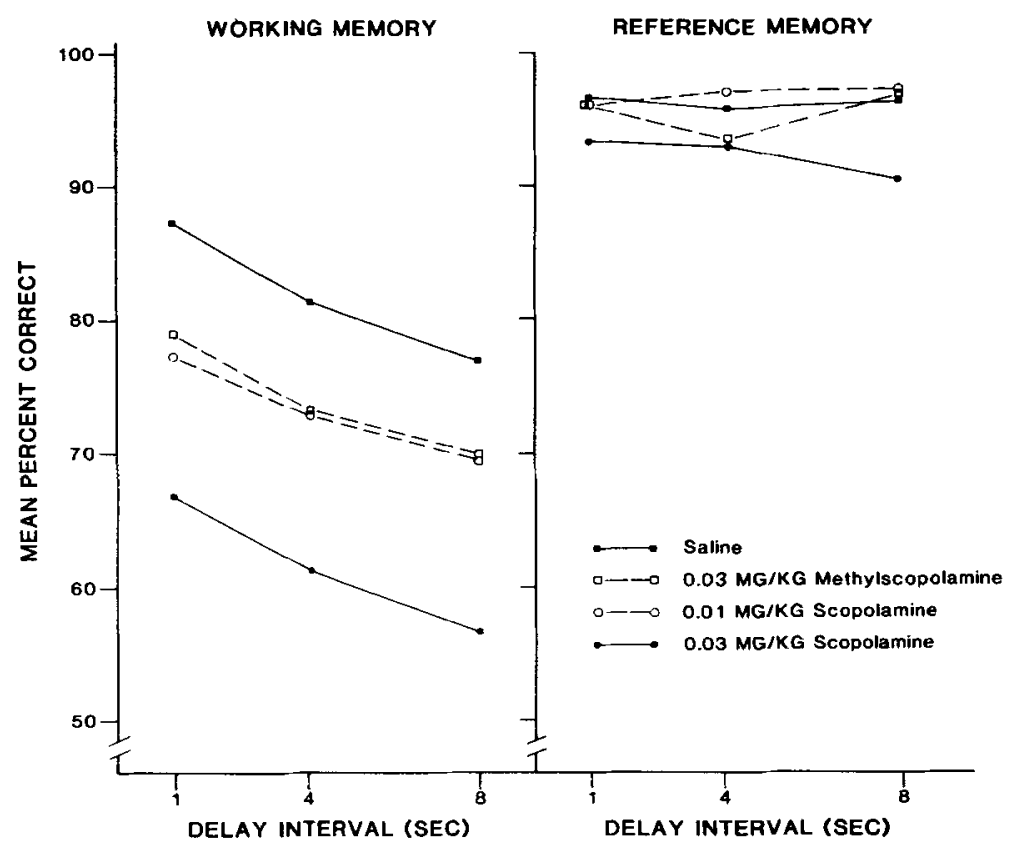

Figure 5. Mean percentage of correct matching responses on workingmemory and reference-memory trials as a function of delay interval and drug condition in Experiment 2.

an intertrial interval of $15 \mathrm{sec}$ was spent in darkness. Each session consisted of 24 working-memory trials and 24 reference-memory trials presented on six individually randomized blocks of the eight different combinations of sample and comparison stimuli counterbalanced for position on the side keys.

All birds were maintained on baseline training until they achieved an overall level of accuracy of $80 \%$ or more on five consecutive sessions. Drug testing was then initiated. On each session, the pigeons received one of the following injections: scopolamine hydrobromide at a dose of 0.01 or $0.03 \mathrm{mg} / \mathrm{kg}$; scopolamine methylbromide at a dose of $0.03 \mathrm{mg} / \mathrm{kg}$; and $0.09 \%$ saline. The injections were made into the pectoral muscle 15-30 min prior to each test session in a volume of $1.0 \mathrm{ml} / \mathrm{kg}$ of body weight. The birds were tested twice at each of the 12 treatment combinations produced by factorially combining the four drug treatment conditions with three delay intervals $(1,4$, and $8 \mathrm{sec})$. Each of the drug treatments was administered once before the same injection was repeated. Two different random orders of the drug treatment conditions were generated. Four birds in the different-sample group and 3 birds in the same-sample group received one order; the remaining birds in both groups received the other order.

\section{Results}

The mean percent correct matching performance during drug testing sessions at the three delay intervals collapsed across the two groups is shown in Figure 5. Accuracy on working-memory trials is shown in the left panel, and accuracy on reference-memory trials is shown in the right panel. An analysis of variance of these data revealed that accuracy on reference memory trials was higher than on working-memory trials $[F(1,11)=69.98$, $M S e=590.60]$. Memory trial type interacted with delay interval $[F(2,22)=13.24, M S e=37.89]$. A simple main effects analysis indicated that increases in delay interval significantly reduced accuracy on working-memory trials $[F(2,22)=22.50]$, but had no effect on the accuracy of reference-memory trials $(F<1)$.

The effect of drug treatment condition was statistically significant $[F(3,33)=24.37, M S e=82.87]$, as was the drug treatment $\times$ memory trial type interaction $[F(3,33)$ $=14.74, M S e=58.33]$. Drug treatment conditions significantly affected both working-memory $[F(3,33)=$ $21.51]$ and reference-memory $[F(3,33)=11.14]$ performance. A Newman-Keuls test indicated that accuracy on working-memory trials was significantly disrupted by injections of scopolamine or methylscopolamine relative to injections of saline. In addition, the $0.03-\mathrm{mg} / \mathrm{kg}$ dose of scopolamine resulted in significantly lower workingmemory performance than the same dose of methylscopolamine or the lower dose of scopolamine. On reference-memory trials, accuracy following an injection of $0.03 \mathrm{mg} / \mathrm{kg}$ of scopolamine was significantly lower than following an injection of $0.01 \mathrm{mg} / \mathrm{kg}$ scopolamine, or $0.03 \mathrm{mg} / \mathrm{kg}$ methylscopolamine, or saline. There was no drug treatment $\times$ delay interval interaction $(F<1)$.

The analysis of variance of the drug testing data also yielded a significant effect of groups $[F(1,11)=15.39$, $M S e=438.70]$ and a groups $\times$ memory trial type interaction $[F(1,11)=7.18, M S e=590.60]$. This interaction is shown in Figure 6. The same-sample group and the different-sample group performed equally well on reference-memory trials $[F(1,11)=1.61]$, but the different-sample group had a much higher level of ac- 


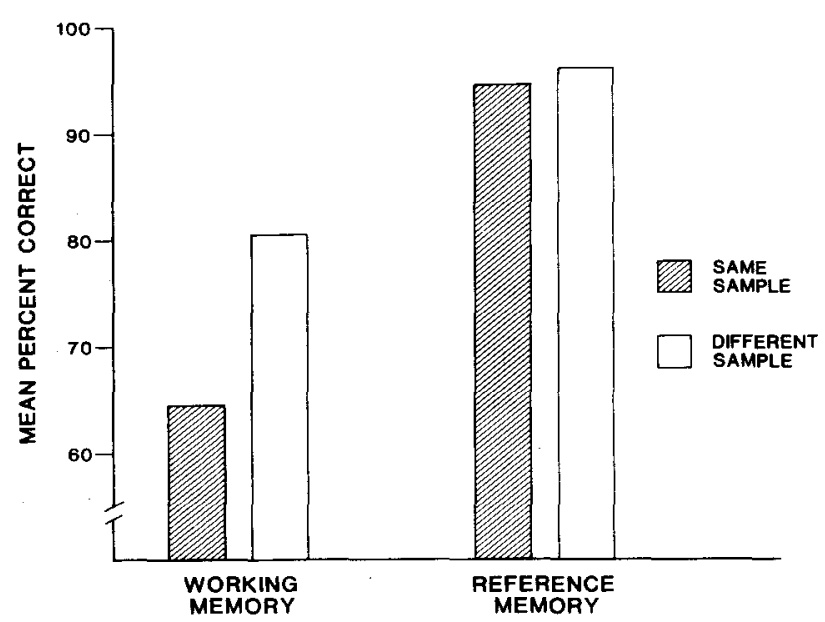

Figure 6. Mean percentage of correct matching responses on working-memory and reference-memory trials for the same-sample group and the different-sample group.

curacy on working-memory trials $[F(1,11)=11.55]$. The groups variable did not interact with any of the other factors in the analysis.

\section{Discussion}

As in Experiment 1, injections of the centrally active form of scopolamine significantly disrupted workingmemory performance more than did the peripherally active form. However, scopolamine also disrupted performance on reference-memory trials. The use of oblique line tilts rather than vertical and horizontal lines did not lower accuracy on reference-memory trials. Accuracy was significantly lower on working-memory trials than on reference-memory trials, even at a 1-sec delay interval under saline conditions. Although in both experiments scopolamine reduced accuracy on working-memory trials more than on reference-memory trials, it is difficult to argue on the basis of these results that cholinergic blockade selectively disrupts working memory. In addition, as in Experiment 1, no drug treatment $x$ delay interval interaction was obtained. Neither dose of scopolamine produced acelerated forgetting on working-memory trials. Thus, the interference with both reference- and workingmemory performance produced by central cholinergic blockade would appear to be due to alterations in the encoding of or retrieval of information rather than the active maintenance of information.

There are two possible explanations for the lower levels of accuracy on working-memory trials obtained in the same-sample group relative to the different-sample group. Since color samples are followed by color comparisons on only half the trials for the same-sample group but on all the trials for the different-sample group, it could be that rehearsal of sample information is reinforced more in the different-samples group. This explanation is somewhat unsatisfactory because several unpublished studies from our laboratory have found that as the number of working memory trials is increased relative to referencememory trials in a different-sample group, accuracy decreases, even though color comparisons follow color samples on all of the trials. An alternative account of the performance difference between the same- and differentsample group is that the repeated presentation of the same two sample stimuli over trials produced a sample encoding deficit in the same-sample group. This interpretation is consistent with Roberts' (1980) finding that performance on homogeneous delayed matching-to-sample trials (i.e., same-sample stimulus on all trials) was better when these trials were mixed with the usual delayed matchingto-sample trials involving stimuli from another dimension than when they occurred alone. The processing deficit in the same-sample group probably reflects difficulty in retrieving the appropriate response decision from reference memory. It is unlikely to be due to decreased rehearsal of information derived from the sample, since increases in delay-interval duration reduced workingmemory performance equivalently in the same-sample and different-sample groups.

\section{GENERAL DISCUSSION}

Previous research has demonstrated that anticholinergic drugs disrupt working-memory performance more than reference memory in radial-arm-maze experiments conducted on small rodents (Levy et al., 1983; Rauch \& Raskin, 1984; Wirsching et al., 1984). In these studies, working-memory errors consisted of reentries into baited arms and reference-memory errors consisted of entries into never-baited arms. Working memory thus requires a conditional discrimination among baited spatial locations, whereas reference memory requires a simple discrimination of never-baited spatial locations. The present research on pigeons attempted to conform to this operationalization. A simple simultaneous visual discrimination constituted the reference-memory task, whereas a delayed conditional visual discrimination constituted the working-memory task. As in the radial-arm-maze experiments, injections of a centrally active anticholinergic had a greater disruptive effect on working-memory trials than on reference-memory trials. However, it is difficult to attribute the effect of scopolamine to a selective impairment of working memory, since a significant drug treatment $x$ delay interval interaction was not obtained in either experiment. Accelerated forgetting of information in working memory attributable to anticholinergic drugs has been reported for rhesus monkeys trained on a visual delayed matching-to-sample task (Penetar \& McDonough, 1983) and for rats trained on a spatial delayed matchingto-sample task (Dunnett, 1985). Recent studies have also shown that anticholinergics and hippocampectomy interfere with temporal working memory and reference memory in rats (Meck, 1983; Meck, Church, \& Olton, 1984). Unlike most studies of spatial memory, in these studies of memory for temporal events, the anticholinergic drugs were administered chronically and then the tests 
were made under saline. It is interesting to note that, under these conditions, effects of anticholinergic drugs are observed with respect to both working and reference memory. Although chronic drug administration was not employed in the present study, scopolamine reduced accuracy on both working-memory and reference-memory trials. On the basis of the present research, it appears that, for pigeons, the disruption produced by central cholinergic blockade is not due to alterations in the active maintenance of information during the delay interval.

\section{REFERENCES}

Aigner, T. G., \& Mishinin, M. (1986). The effects of physostigmine and scopolamine on recognition memory in monkeys. Behavioral \& Neural Biology, 45, 81-87.

APRISON, M. H., \& TAKAHASHI, R. (1965). Biochemistry of the avian central nervous system: II. 5-Hydroxytryptamine, acetylcholine, 3,4-dehydroxyphenylamine and norepinephrine in several discrete areas of the pigeon brain. Journal of Neurochemistry, 12, 221-230.

Bartus, R. T., Dean, R. L., Beer, B., \& LipPa, A. S. (1982). The cholinergic hypothesis of geriatric memory dysfunction. Science, 217, 408-417.

Bartus, R. T., \& Johnson, H. R. (1976). Short-term memory in the rhesus monkey: Disruption from the anticholinergic scopolamine. Pharmacology, Biochemistry \& Behavior, 5, 39-46.

BEATTY, W. W., \& BieRLEY, R. A. (1985). Scopolamine degrades spatial working memory but spares spatial reference memory: Dissimilarity of anticholinergic effect and restriction of distal visual cues. Pharmacology, Biochemistry \& Behavior, 23, 1-6.

Bohdanecky, Z., Jarvik, M. E., \& Carley, J. L. (1967). Differential impairment of delayed matching in monkeys by scopolamine and scopolamine methylbromide. Psychopharmacologia, 11, 293-299.

CarTer, D. E., \& Eckerman, D. A. (1975). Symbolic matching by pigeons: Rate of learning complex discriminations predicted from simple discriminations. Science, 187, 662-664.

DunNetT, S. B. (1985). Comparative effects of cholinergic drugs and lesions of nucleus basalis or fimbria-fornix on delayed matching in rats. Psychopharmacology, 87, 357-363.

Eckerman, D. A., Gordon, W. A., Edwards, J. D., MacPhail, R. C., \& GAGE, M. (1980). Effects of scopolamine, pentobarbital and amphetamine on radial arm maze performance in the rat. Pharmacology, Biochemistry \& Behavior, 12, 595-602.

HoNIG, W. K. (1978). Studies of working memory in the pigeon. In S. H. Hulse, H. Fowler, \& W. K. Honig (Eds.), Cognitive processes in animal behavior (pp. 211-248). Hillsdale, NJ: Erlbaum.

HoNIG, W. (1984). Contributions of animal memory to the interpretation of animal learning. In H. L. Roitblat, T. G. Bever, \& H. S. Terrace (Eds.), Animal cognition (pp. 24-44). Hillsdale, NJ: Erlbaum.

Hyman, B. T., Van Hoesen, G. W., Damasio, A. R., \& Barnes, C. L. (1984). Alzheimer's disease: Cell specific pathology isolates the hippocampal formation. Science, 225, 1168-1170.

Levy, A., Kluge, P. B., \& ElSMORE, T. F. (1983). Radial arm maze performance of mice: Acquisition and atropine effects. Behavioral \& Neural Biology, 39, 229-240.

Maki, W. S., Riley, D. A., \& Leith, C. R. (1976). The role of test stimuli in matching to compound samples by pigeons. Animal Learning \& Behavior, 4, 13-21.

MrCK, W. H. (1983). Selective adjustment of the speed of the internal clock and memory processes. Journal of Experimental Psychology: Animal Behavior Processes, 9, 171-201.
Meck, W. H., Church, R. M., \& Olton, D. S. (1984). Hippocampus, time, and memory. Behavioral Neuroscience, 98, 3-22.

Nelson, K. R., \& Wasserman, E. A. (1978). Temporal factors influencing the pigeons' successive matching-to-sample performance: Sample duration, intertrial interval and retention interval. Journal of the Experimental Analysis of Behavior, 30, 153-162.

Olton, D. S., \& PaPas, B. C. (1979). Spatial memory and hippocampal function. Neuropsychologia, 17, 669-682.

Penetar, D. M., \& MCDonough, J. H. (1983). Effects of cholinergic drugs on delayed match-to-sample performance of rhesus monkeys. Pharmacology, Biochemistry \& Behavior, 19, 963-967.

RaUCH, S. L., \& RASKIN, L. A. (1984). Cholinergic mediation of spatial memory in the preweanling rat: Application of the radial arm maze paradigm. Behavioral Neuroscience, 98, 35-43.

RoBERTS, W. A. (1972). Short-term memory in the pigeon: Effects of spacing and repetition. Journal of Experimental Psychology, 94, 74-83.

ROBERTS, W. A. (1980). Distribution of trials and intertrial retention in delayed matching-to-sample with pigeons. Journal of Experimental Psychology: Animal Behavior Processes, 6, 217-237.

RoBERTS, W. A., \& GRANT, D. S. (1976). Studies of short-term memory in the pigeon using the delayed matching-to-sample procedure. In D. L. Medin, W. A. Roberts, \& R. T. Davis (Eds.), Processes of animal memory (pp. 79-119). Hillsdale, NJ: Erlbaum.

Roitblat, H. L. (1982). The meaning of representation in animal memory. Behavioral \& Brain Sciences, 5, 353-406.

RoITBLAT, H. L. (1984). Representations in pigeon working memory. In H. L. Roitblat, T. G. Bever, \& H. S. Terrace (Eds.), Animal cognition (pp. 79-98). Hillsdale, NJ: Erlbaum.

Santi, A., Grossi, V., \& Gibson, M. (1982). Differences in matchingto-sample performance with element and compound sample stimuli in pigeons. Learning \& Motivation, 13, 240-256.

Sidman, M., Stoddard, L. T., \& Mohr, J. P. (1968). Some additional quantitative observations of immediate memory in a patient with bilateral hippocampal lesions. Neuropsychologia, 6, 245-254.

STEvens, R. (1981). Scopolamine impairs spatial maze performance in rats. Physiology \& Behavior, 27, 385-386.

Teal, J. J., \& Evans, H. L. (1982). Effects of DDAVP, a vasopressin analog, on delayed matching behavior in the pigeon. Pharmacology, Biochemistry \& Behavior, 17, 1123-1127.

WALKER, J. A., \& OltoN, D. S. (1984). Fimbria-fornix lesions impair spatial working memory but not cognitive mapping. Behavioral Neuroscience, 98, 226-242.

Watts, J., Stevens, R., \& Robinson, C. (1981). Effects of scopolamine on radial maze performance in rats. Physiology \& Behavior, 26, 845-851.

WiLliams, B. A. (1971). The effects of intertrial interval on discrimination reversal learning in the pigeon. Psychonomic Science, 23, 241-243.

Williams, B. A. (1976). Short-term retention of response outcome as a determinant of serial reversal learning. Learning \& Motivation, 7 , 418-430.

Wirsching, B. A., Beninger, R. J., Jhamandas, K., Boggman, R. J., \& EL-DefrawY, S. R. (1984). Differential effects of scopolamine on working and reference memory of rats in the radial maze. Pharmacology, Biochemistry \& Behavior, 20, 659-662.

Zola-Morgan, S., Souire, L. R., \& Mishkin, M. (1982). The neuroanatomy of amnesia: Amygdala-hippocampus versus temporal stem. Science, 218, 1337-1339.

(Manuscript received September 17, 1986; revision accepted for publication May 1, 1987.) 